\title{
PRELIMINARY ANALYSIS KESULITAN MAHASISWA S-1 PGSD DALAM MEREVIEW ARTIKEL ILMIAH PADA JURNAL
}

\author{
Muhammad Syazali ${ }^{1, *}$, Lalu Hamdian Affandi ${ }^{2)}$, Nursaptini ${ }^{3)}$, Aisa Nikmah Rahmatih ${ }^{4)} \&$ Fitri Puji \\ Astria $^{5)}$ \\ 1), 2), 3), 4), 5) Universitas Mataram, Mataram, Indonesia \\ E-mail: m.syazali@unram.ac.id
}

\begin{tabular}{ll}
\hline ARTICLE INFO & ABSTRACT \\
\hline Article history & Reviewing scientific articles published in journals is a competency needed \\
Received: August 2, 2020 & by students to improve their writing skills. As a form of implementation of \\
Revised: August 3, 2020 & Higher Education Tri Dharma in the field of education, lecturers are \\
Accepted: August 12,2020 & responsible for training students to review articles. To provide optimal \\
learning facilities, information is needed related to student difficulties in & reviewing articles in journals. This study aims to diagnose the difficulties of \\
Keywords: & undergraduate students at PGSD FKIP Mataram University in reviewing \\
student difficulties, problem, & scientific articles in journals. The study was conducted on S1 students of \\
method, article review & PGSD FKIP Mataram University who programed Quantitative Research \\
& Methods courses. The research subject of 36 students was determined using \\
a purposive sampling technique. Data collection is done by assigning \\
students to review 1 scientific article published by a SINTA accredited \\
journal. The results of the review by students were analyzed descriptively to \\
determine the location of student difficulties. The results showed that the \\
largest proportion of student difficulties lies in the research method \\
(86.11\%), then the research problem (44.44\%), and the smallest proportion \\
is the research result (5.56\%). Information from the results of this study can \\
be used as a reference for providing learning facilities to improve student \\
review skills. This skill can help students in completing theses which have \\
been a problem for many undergraduate students at PGSD FKIP Mataram \\
University.
\end{tabular}

\section{A. PENDAHULUAN}

Pendahuluan Mereview artikel ilmiah yang dipublikasi di jurnal merupakan kompetensi yang dibutuhkan oleh mahasiswa untuk meningkatkatkan keterampilan menulis (Parmin, 2012). Mereview artikel juga berpotensi untuk melatih berpikir kritis, ketelitian, kejelian, meningkatkan kemampuan analisis (Sholihah, 2018), dan meminimalisasi plagiasi mahasiswa (Rosalia \& Fuad, 2019). Peningkatan berbagai kompetensi tersebut akhirnya akan bermanfaat secara langsung pada saat mahasiswa memprogramkan mata kuliah skripsi. Mata kuliah ini merupakan prasyarat untuk menyelesaikan program S-1 di Universitas Mataram (Tim Penyusun, 2019). Dari skripsinya tersebut, mahasiswa diminta untuk menulis dalam format artikel ilmiah. Jika memungkinkan artikel akan dipublikasi di jurnal nasional atau internasional. 
Artikel ilmiah, terutama yang diterbitkan oleh jurnal terkareditasi SINTA, adalah produk hasil penelitian atau telaah literatur (literature review). Artikel ilmiah hasil penelitian umumnya terdiri dari bagian abstrak, pendahuluan, metode, hasil dan pembahasan, dan kesimpulan (Persadha, 2016; Uchtiawati et al., 2014; Zuriati, 2017). Untuk tujuan pengutipan, yang dibutuhkan adalah hasil penelitian, dan cukup dengan membaca bagian abstrak (Harsoono et al., 2019; Heriyanto, 2018). Namun untuk tujuan meningkatkan kompetensi mahasiswa dalam penelitian, minimal membutuhkan bagian masalah, metode dan hasil penelitian. Kemampuan mengidentifikasi masalah dibutuhkan oleh mahasiswa karena merupakan langkah awal melakukan penelitian (Arikunto, 2014; Sugiyono, 2018).

Mengidentifikasi dan menemukan masalah membutuhkan keterampilan mengamati. Keterampilan ini dapat dicontohkan pada fenomena jatuhnya buah apel. Bagi banyak orang, fenomena jatuhnya apel ke bawah adalah hal biasa. Namun bagi Newton, fenomena tersebut adalah masalah, dan mengantarkannya pada teori gravitasi. Mengamati tidak hanya mencakup melihat obyek menggunakan mata, namun juga dapat dilakukan dengan mendengar, mengecap rasa, mengenali bau, dan menentukan kasar atau halusnya suatu permukaan. Di dalam Permendikbud (2018) tertera bahwa mengamati mencakup membaca, mendengarkan, dan berbagai hal yang melibatkan indera. Pada konteks review artikel, salah satu keterampilan mengamati yang perlu ditingkatkan oleh mahasiswa adalah membaca. Untuk tujuan tersebut, dosen dapat memfasilitasi mahasiswa melalui pembelajaran dalam proses perkuliahan.

Perkuliahan merupakan salah satu dharma perguruan tinggi di bidang pendidikan dan pengajaran. Sebagai bentuk pelaksanaan Tri Dharma Perguruan Tinggi di bidang tersebut, dosen bertanggungjawab dalam melatih mahasiswa untuk mereview artikel. Untuk memberikan treatment yang tepat, diperlukan informasi terkait kesulitan yang dialami mahasiswa dalam mereview artikel. Kegiatan mereview artikel juga dapat menjadi pembelajaran bagi mahasiswa di luar kelas melalui tatap muka. Referensi berupa artikel ilmiah dari hasil penelitian mensuport visi Universitas Mataram yang menekankan pada pendidikan berbasis riset (Tim Penyusun, 2019).

Tujuan dari penelitian ini adalah mendiagnosa kesulitan mahasiswa dalam mereview artikel ilmiah yang dipublikasi oleh jurnal terakreditasi SINTA. Informasi dari hasil penelitian ini dapat dijadikan acuan untuk memberikan fasilitas pembelajaran yang terbaik bagi mahasiswa. Manfaatnya adalah mahasiswa memiliki keterampilan yang baik dalam mereview artikel ilmiah. Kompetensi tersebut diharapkan dapat berpengaruh positif terhadap wawasan mahasiswa terkait masalah-masalah penelitian, metode penelitian yang dapat digunakan dalam penyelidikan ilmiah, dan hasil penelitian yang merupakan sumber primer. Kompetensi 
mereview artikel juga diharapkan dapat membantu mahasiswa dalam menyelesaikan skripsi yang selama ini menjadi problem bagi banyak mahasiswa S-1 PGSD FKIP Universitas Mataram.

\section{B. METODE PENELITIAN}

Jenis penelitian ini adalah penelitian deskriptif. Studi dilakukan pada mahasiswa S-1 PGSD, FKIP Universitas Mataram. Subjek penelitian berjumlah 36 mahasiswa kelas IV B Pagi yang memprogramkan matakuliah metode penelitian kuantitatif. Pengumpulan data dilakukan dengan menugaskan kmahasiswa untuk mereview 1 artikel ilmiah yang dipublikasi melalui jurnal terakreditasi SINTA. Dari artikel yang direview, mahasiswa diminta untuk menuliskan masalah, metode dan hasil penelitian. Untuk mendiagnosa kesulitannya, mahasiswa diminta untuk mengumpulkan artikel dan hasil review-nya.

Artikel yang dikumpulkan direview sebagai standar (RS) untuk menilai hasil review yang dilakukan oleh mahasiswa (RM). Mahasiswa dikatagorikan mengalami kesulitan apabila terdapat perbedaan antara RM dan RS. Letak kesulitan yang ditemukan dianalisis lebih lanjut untuk mengetahui pemahaman awal mahasiswa. Data hasil diagnosa kesulitan mahasiswa dianalisis secara deskriptif untuk mengetahui proporsinya. Persamaan yang digunakan adalah:

$$
P_{i}=\frac{n_{i}}{N} \times 100 \%
$$

Dimana:

$P_{i} \quad$ : Proporsi aspek i (\%)

$n_{i} \quad$ : Jumlah aspek i

$N \quad$ : Jumlah total aspek

\section{HASIL DAN PEMBAHASAN}

\section{Hasil Penelitian}

Proporsi terbesar kesulitan mahasiswa dalam mereview artikel adalah menentukan metode penelitian $(86.11 \%)$, diikuti oleh masalah penelitian, dan proporsi terkecil adalah hasil penelitian (Gambar 1). Kompetensi mahasiswa terkait metode penelitian masih terbatas pada konsep metode kualitatif dan kuantitatif. Terdapat mahasiswa yang memahami metode sebagai desain dan jenis penelitian (Gambar 2). Walaupun proporsinya masih di bawah metode penelitian, namun variasi pengetahuan mahasiswa terhadap masalah penelitian merupakan yang paling besar (Gambar 3). terkait kesulitan dalam menentukan hasil penelitian, mahasiswa 
Syazali, dkk. (2020). Preliminary Analysis Kesulitan...

memahaminya sebagai masalah peneltian. Ada juga yang tidak menuliskan hasil penelitian pada lembar tugasnya.

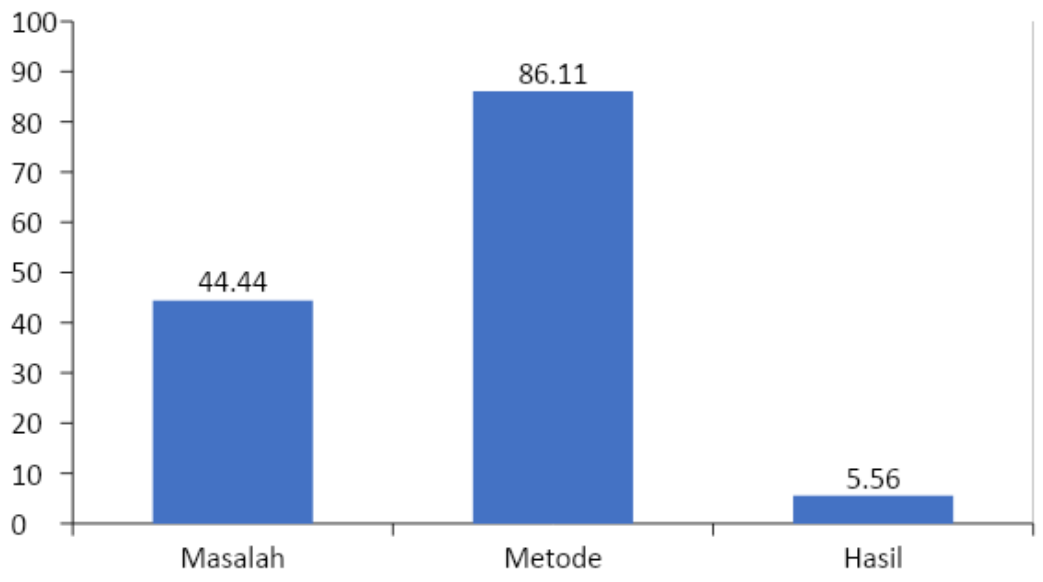

Gambar 1. Proporsi aspek kesulitan mahasiswa dalam mereview artikel ilmiah

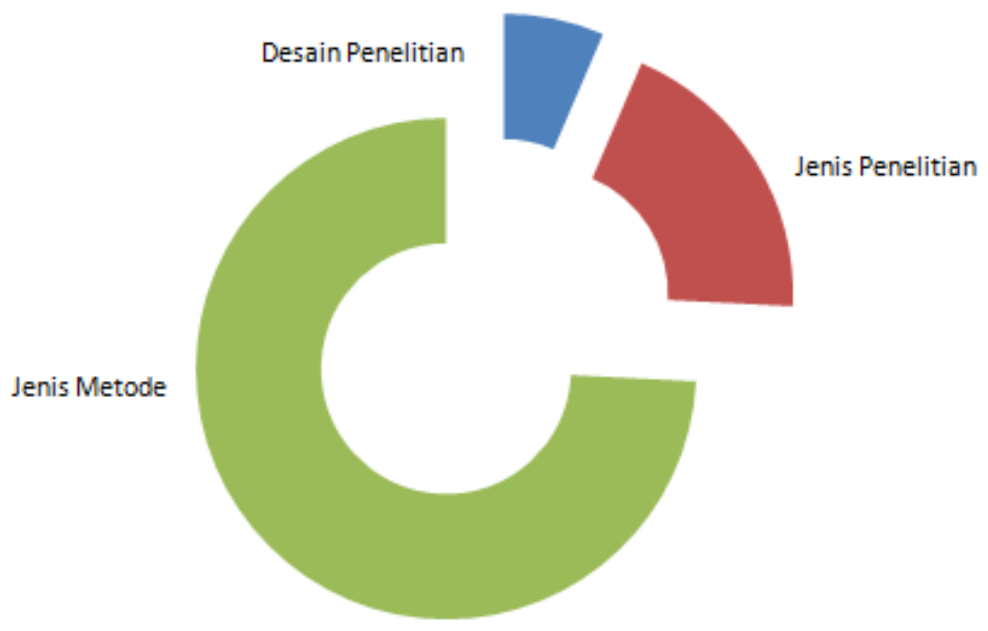

Gambar 2. Proporsi miskonsepsi mahasiswa pada aspek metode penelitian

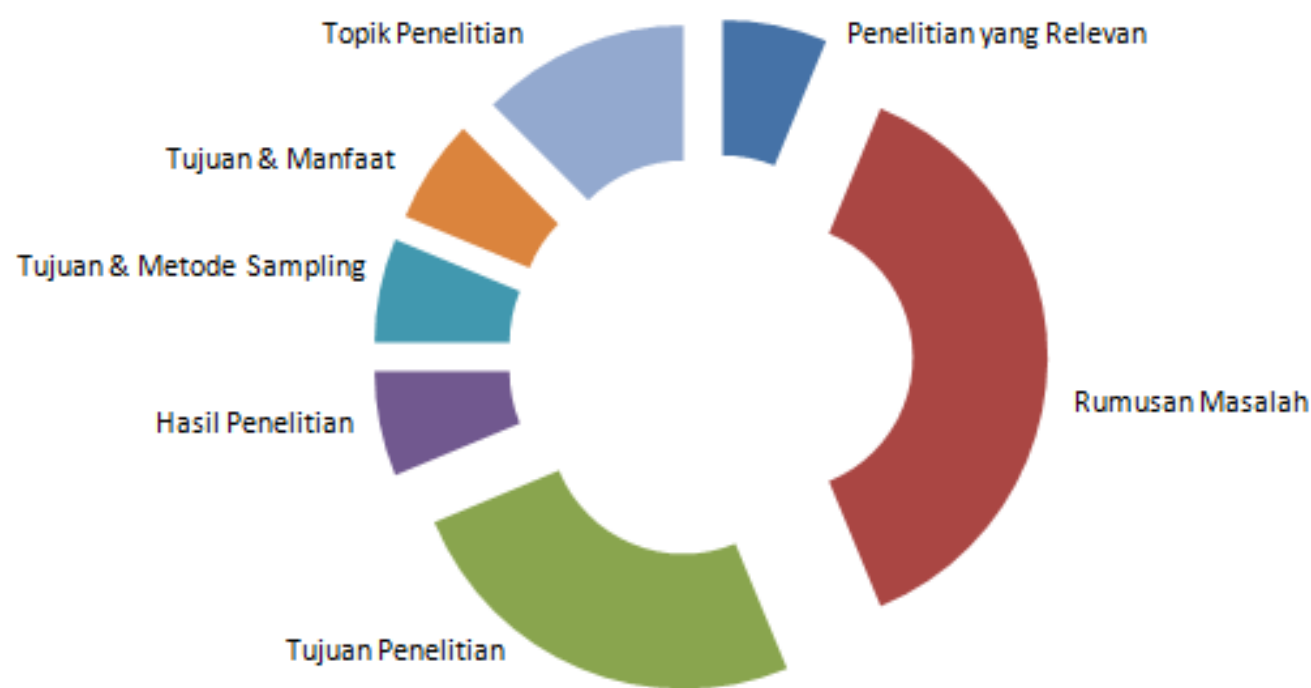

Gambar 3. Proporsi miskonsepsi mahasiswa pada aspek masalah penelitian 


\section{Pembahasan}

Kesulitan terbesar mahasiswa dalam mereview artikel di jurnal adalah menuliskan metode penelitian (Gambar 1). Ditinjau dari aspek perkuliahan Metode Penelitian Kuantitatif yang baru dua kali pertemuan, maka pengetahuan mahasiswa yang masih terbatas adalah faktor penyebabnya. Walaupun demikian, sebenarnya disemester 3 mereka pernah memprogramkan mata kuliah Metode Penelitian Kualitatif. Artinya, mahasiswa memiliki kemampuan awal terhadap metode penelitian. Beberapa di antaranya sudah memiliki pengetahuan yang cukup sehingga terdapat mahasiswa (15.89\%) yang mengerjakan tugas pada bagian ini dengan benar. Fakta ini menunjukkan penyebab lain yaitu mahasiswa sudah lupa dengan konsep metode penelitian.

Kompetensi mahasiswa dalam menuliskan metode penelitian masih terbatas pada konsep jenis metode (Gambar 2). Hal ini tersurat pada tugas mereka yang hanya menuliskan metode kualitatif, metode kuantitatif, atau mix method. Namun ada juga yang memahami metode penelitian sebagai jenis atau desain penelitian. Di bagian metode pada artikel ilmiah, sedikitnya mencakup jenis penelitian, teknik sampling, metode pengumpulan data, dan analisis data (see in Fadiana et al., 2019; Haryani, 2019; Susilo et al., 2019). Terdapat banyak artikel yang mencantumkan lokasi dan peta pengumpulan sampel (Ilhamdi et al., 2020; Kennedi et al., 2020; Suana et al., 2020). Sub-bagian yang ada pada metode bervariasi tergantung pada jenis penelitian, dan kebijakan masing-masing jurnal (see in Saleh \& Mazlan, 2019; Simangunsong, 2019). Keberagaman tersebut dapat menjadi salah satu penyebab adanya perbedaan pemahaman mahasiswa terhadap konsep metode penelitian.

Proporsi kesulitan mahasiswa terkait metode memang yang paling besar, namun miskonsepsi terhadap permasalahan penelitian adalah yang paling variatif. Masalah penelitian secara predominan dipahami oleh mahasiswa sebagai rumusan masalah dan tujuan penelitian (Gambar 3). Miskonsepsi ini terjadi karena kurangnya kompetensi terhadap konsep masalah dalam penelitian. Hal tersebut juga dapat disebabkan oleh faktor literasi membaca yang masih rendah. Terdapat artikel ilmiah yang masalah penelitiannya secara jelas tersurat di bagian pendahuluan (Milla et al., 2019; Rosidin et al., 2019; Saleh \& Mazlan, 2019). Namun ada juga artikel yang masalah penelitiannya tersirat. Selain itu, masalah yang diungkap pada artikel ilmiah berbeda tergantung pada bidang kajian (Hastuti et al., 2019; Hocking \& Babbitt, 2014), dan urgenitas suatu permasalahan.

Permasalahan, metode dan hasil penelitian adalah bagian-bagian dari artikel ilmiah yan saling terkait. Walaupun memiliki proporsi yang paling rendah (Gambar 1), namun semua 
mahasiswa yang kesulitan dalam menentukan hasil penelitian adalah mereka yang kesulitan menemukan masalah dan metode penelitian. Hasil penelitian dalam artikel sangat mudah ditemukan dalam artikel ilmiah. Bagian ini ada pada abstrak (see in Nursaptini et al., 2020; Rahmatih et al., 2020), dan pada bagian hasil dan pembahasan (see in Mardiana \& Syazali, 2020). Umumnya disajikan dalam bentuk tabel atau grafik (see in Doyan et al., 2020; Milla et al., 2019; Ramdani et al., 2020). Faktor inilah yang menyebabkan hampir semua mahasiswa menulis dengan benar pada lembar tugasnya. Adanya mahasiswa yang kesulitan dalam menemukan hasil penelitian, dan masalah \& metode penelitian pada artikel ilmiah menunjukkan bahwa mereka membutuhkan fasilitas pembajaran yang dapat meningkatkan kompetensinya dalam mereview artikel ilmiah.

\section{SIMPULAN}

Kesulitan mahasiswa dalam mereview artikel dijurnal terdapat pada aspek menentukan masalah, metode, dan hasil penelitian. proporsi terbesar terletak di metode penelitian $(86.11 \%)$, kemudian masalah penelitian (44.44\%), dan proporsi terkecil adalah hasil penelitian $(5.56 \%)$.

\section{DAFTAR PUSTAKA}

Arikunto, S. (2014). Prosedur Penelitian: Suatu Pendekatan Praktik. Jakarta: Rineka CIpta.

Doyan, A., Jufri, A. W., Hardiyansyah, A., Auliya, K., Hakim, S., \& Muliyadi, L. (2020). Development of learning media of microscope portable auto design to increase student's problem- solving ability in light and optical tools topic. Advances in Social Science, Education and Humanities Research, 438, 300-302.

Fadiana, M., Amin, S. M., Lukito, A., Wardhono, A., \& Aishah, S. (2019). Assessment of seventh grade students' capacity of logical thinking. Jurnal Pendidikan IPA Indonesia, 8(1), 75-80. https://doi.org/10.15294/jpii.v0i0.11644

Harsoono, Z. A. R., Hertanto, M. I., Barisfallah, T. D., Dharm, R. A., Ramadhanty, D., Pambudi, H. D., \& Puspa, T. (2019). Review perkembangan riset topik kerjasama tim selama sepuluh tahun terakhir pada jurnal online. Seminar Nasional Cendekiawan; Buku 2 "Sosial Dan Humaniora “, 2-6.

Haryani, S. (2019). Students' satisfaction index on chemistry learning process. Jurnal Pendidikan IPA Indonesia, 8(1), 101-109. https://doi.org/10.15294/jpii.v8i1.15331

Hastuti, D., Alfiasari, Hernawati, N., Oktriyanto, \& Puspitasari, M. D. (2019). Effectiveness of "PIK-R" program as an extracurricular for high/vocational school students in 
Syazali, dkk. (2020). Preliminary Analysis Kesulitan...

preventing negative behaviors of adolescents. Cakrawala Pendidikan, 38(1), 1-15. https://doi.org/10.21831/cp.v38i1.22283

Heriyanto. (2018). Memahami bagaimana mahasiswa melakukan penelusuran informasi melalui academic databases. ANUVA, 2(4), 369-376.

Hocking, D. J., \& Babbitt, K. J. (2014). Amphibian contributions to ecosystem services. Herpetological Conservation and Biology, 9(1), 1-17.

Ilhamdi, M. L., Idrus, A. A. L., Santoso, D., \& Hadiprayitno, G. (2020). Short Communication: Community structure and diversity of Odonata in Suranadi Natural Park, West Lombok Indonesia. $\quad$ Biodiversitas, 21(2), 718-723. https://doi.org/10.13057/biodiv/d210238

Kennedi, U. F., Kusrini, M. D., Ariefiandy, A., \& Mardiastuti, A. (2020). Invasive toads are close to but absent from Komodo National. BIO Web of Conferences, 00017, 1-5. https://doi.org//10.1051/bioconf/20201900017

Mardiana, I., \& Syazali, M. (2020). Implementasi model pembelajaran kooperatif tipe snowball throwing untuk meningkatkan hasil belajar ipa. Jurnal Pi, 15(1), 50-53.

Milla, D., Jufri, A., \& Soeprianto, H. (2019). The effectiveness pf project-based learning for biology class in developing the science processing skills and creativity of high school students. Unnes Science Education Journal, 8(1), 25-30.

Nursaptini, Syazali, M., Sobri, M., Sutisna, D., \& Widodo, A. (2020). Profil kemandirian belajar mahasiswa dan analisis faktor yang mempengaruhinya: Komunikasi orang tua dan kepercayaan diri. Jurnal Pendidikan Edutama, 7(1), 85-94.

OECD2.pdf. (n.d.).

Parmin. (2012). Penerapan critical review artikel pembelajaran IPA untuk meningkatkan kemampuan mahasiswa dalam menyusun proposal skripsi. Jurnal Pendidikan IPA Indonesia, 1(2), 183-191.

Penyusun, T. (2019). Pedoman Akademik Universitas Mataram. Mataram: Mataram University Press.

Permendikbud. (2018). Permendikbud RI Nomor 37 Tahun 2018 tentang Perubahan atas Peraturan Menteri Pendidikan dan Kebudayaan Nomor 24 Tahun 2016 tentang Kompetensi Inti dan Kompetensi Dasar Pelajaran pada Kurikumlum 2013 pada Pendidikan Dasar dan Pendidikan Menengah (No. 37). Salinan Permendikbud.

Persadha, D. A. K. (2016). Studi kompetensi kemampuan menulis di kalangan mahasiswa. MUADDIB, 06(01), 1-20. 
Syazali, dkk. (2020). Preliminary Analysis Kesulitan...

Rahmatih, A. N., Maulyda, M. A., \& Syazali, M. (2020). Refleksi nilai kearifan lokal (local wisdom) dalam pembelajaran sains sekolah dasar: Literature review. Jurnal Pijar MIPA, 15(2), 151-156. https://doi.org/10.29303/jpm.v15i2.1663

Ramdani, A., Jufri, A. W., \& Setiadi, D. (2020). Kemampuan berpikir kritis dan penguasaan konsep dasar IPA peserta didik. Jurnal Penelitian Pendidikan IPA, 21(1), 119-124. https://doi.org/10.29303/jppipa.v6i1.388

Rosalia, R., \& Fuad, J. (2019). Peran dosen dalam meminimalisasi perilaku plagiasi mahasiswa. Indonesian Journal of Islamic Education Studies, 2(1), 61-77. https://doi.org/10.33367/ijies.v2i1.882

Rosidin, U., Kadaritna, N., \& Hasnunidah, N. (2019). Can argument-driven inquiry models have impact on critical thinking skills for students with different personality types? Cakrawala Pendidikan, 38(3), 511-526. https://doi.org/10.21831/cp.v38i3.24725

Saleh, S., \& Mazlan, A. (2019). The effects of brain-based teaching with i-think maps and brain gym approach towards physics understanding. Jurnal Pendidikan IPA Indonesia, 8(1), 12-21. https://doi.org/10.15294/jpii.v8i1.16022

Sholihah, U. (2018). Teknik peer-review melalui google docs: alternatif piranti kolaborasi dalam menulis. Widya Wacana, 13(2), 61-68.

Simangunsong, E. (2019). Factors determining the quality management of higher education: a case study at a business school in indonesia. Cakrawala Pendidikan, 38(3), 452464. https://doi.org/10.21831/cp.v38i3.26598

Suana, I. W., Ahyadi, H., Hadiprayitno, G., Amin, S., Tan, L. A., Wangsajati, T., Kalih, S., \& Sudaryanto, F. X. (2020). Environment carrying capacity and willingness to pay for bird- watching ecotourism in Kerandangan Natural Park, Lombok, Indonesia. Biodiversitas, 21(5), 2266-2274. https://doi.org/10.13057/biodiv/d210557

Sugiyono. (2018). Metode Penelitian Kuantitatif, Kualitatif, dan R\&D. Bandung: Alfabeta.

Susilo, H., Hastuti, U. S., \& Lestari, U. (2019). The efforts to foster students' skill in making questions through thinking tool (question matrix) development. Jurnal Pendidikan IPA Indonesia, 8(1), 119-128. https://doi.org/10.15294/jpii.v8i1.15347

Uchtiawati, S. R. I., Edy, S., \& Arif, Z. M. (2014). Analisis kemandirian dan tanggung jawab dalam penerapan mata kuliah metodologi penelitian. Didaktika, 21(1), 28-36.

Zuriati, D. (2017). MENARA Ilmu Vol. XI Jilid 1 No.74 Januari 2017. XI (74), 7-18. 